\title{
COMPARATIVE AGGRESSION IN SCELOPORUS VIRGATUS, S. UNDULATUS CONSOBRINUS, AND S. U. TRISTICHUS (SAURIA: IGUANIDAE)
}

\author{
BY MARIAN B. VINEGAR \\ Museum of Zoology, University of Michigan, Ann Arbor, Michigan*
}

\begin{abstract}
Aggressive behaviour in both sexes of Sceloporus virgatus, $S$. undulatus consobrinus, and $S . u$. tristichus were compared by introducing a conspecific to a resident lizard in the field. Males of $S$. $u$. consobrinus exhibited high intensity aggression more commonly than did males of the other forms. Of the females, $S$. $u$. tristichus showed the greatest propensity for aggressive behaviour; $S$. $u$. consobrinus showed the least. In males, degree of aggression was correlated positively with degree of sexual dichromatism. The high degree of aggression in male $S$. $u$. consobrinus may be selectively advantageous because of (1) low density increasing space between females, (2) low density reducing selection against a relatively high frequency of violent fighting, and (3) high predation favouring lizards that do not leave their sites upon intrusion of another male. High aggression in female $S$. $u$. tristichus may be selectively advantageous because of (1) higher density leading to reduced food supply and fewer egglaying sites, and (2) lower predation reducing selection against mobility and fighting in females.
\end{abstract}

Natural selection should favour a particular level of aggression between conspecific organisms of the same sex within a population. Aggression is related closely to the ability to compete for mates, food, space, or other resources. An animal that is not aggressive enough may lose in competition for these resources. An animal that is too aggressive, however, may not spend enough energy in food-getting, mating, predator avoidance, or other adaptive activities, and would be at a disadvantage relative to a less aggressive animal. The level of aggression that is most adaptive should be related to such features as the population density, survivorship, sex ratio, food supply, physical characteristics of the environment, and possibly sexual dimorphism.

This study determines aggressive behaviour in three closely related forms of the lizard genus Sceloporus that differed in habitat, population structure, and sexual dichromatism. Differences in level of aggression are related to differences in environmental biology, Therefore, insight into the evolution of aggressive behaviour is gained by comparing selective pressures on these lizards.

\section{Animals}

\section{Methods}

Sceloporus virgatus, S. undulatus consobrinus, and $S$. u. tristichus, all less than $80 \mathrm{~mm}$ in snoutvent length, were compared. Males tend to be

\footnotetext{
*Present address: Department of Environmental Health, Kettering Laboratory, University of Cincinnati, Medical Center, Cincinnati, Ohio 45267.
}

smaller than females. Sceloporus u. consobrinus is the largest of the three forms; $S$. virgatus is the smallest.

Males of $S$. undulatus have a blue patch on each side of the throat and belly. Females of $S$. $u$. consobrinus have blue throat patches but no blue belly patches. Females of $S$. u. tristichus, however, have blue belly patches that tend to be lighter than those of the males, as well as blue throat patches. Both $S$. virgatus males and females have no belly patches; males and nonproductive females have blue throat patches. During the breeding season, however, the blue throat patches of reproductive females are surrounded or replaced by orange.

\section{Study Areas}

All forms were studied where they seemed most abundant in south-eastern Arizona and south-western New Mexico. Sceloporus virgatus was studied in two areas in Cave Creek Canyon, Cochise County, Arizona. One area by a road was vulnerable to disturbance. The elevation was $1646 \mathrm{~m}$, and this area was $0.40 \mathrm{~km}$ away from the Southwestern Research Station. The other area was about $0.40 \mathrm{~km}$ away from a road, and was rarely disturbed by people. The elevation was $1798 \mathrm{~m}$ and this area was $2.90 \mathrm{~km}$ from the Southwestern Research Station. Both areas were along a tributary (North Fork) of Cave Creek. The creek ran intermittently, and the creek bed contained, and was surrounded by, boulders. The principal tree species in both areas were ponderosa pine (Pinus ponderosa), Apache pine 
(Pinus engelmannii), alligator juniper (Juniperus deppeana), Arizona white oak (Quercus arizonica) and sycamores (Platanus wrightii). The uneven nature of the terrain made precise measurements impossible, but each area was approximately one hectare. Other lizard species present, in apparent order of abundance, were Urosaurus ornatus, Cnemidophorus sp., Sceloporus jarrovi (less abundant in the upper study area than in the lower), Sceloporus clarki, and Phrynosoma douglassi. Gerrhonotus kingi and Eumeces obsoletus were not seen on the study areas but were seen in similar habitats nearby.

Sceloporus undulatus consobrinus was studied in a desert-grassland $16.89 \mathrm{~km}$ north of Lordsburg, Hidalgo County, New Mexico, at an elevation of $1219 \mathrm{~m}$. The dominant vegetation included yucca (Yucca elata), Mormon-tea (Ephreda sp.), and mesquite (Prosopis sp.). The $S$. $u$. consobrinus were usually found in the yuccas. The area was bordered by an arroyo along which grew desert willow (Chilopsis linearis) and by New Mexico Highway 464. This area was $4 \cdot 25$ ha. Other lizard species present included Cnemidophorus tigris, Phrynosoma cornutum, Crotaphytus wislizenii, and Holbrookia maculata.

Sceloporus $u$. tristichus was studied in the Pinos Altos mountains $1.61 \mathrm{~km}$ north of Pinos Altos, Grant County, New Mexico, in the Gila National Forest at an elevation of $2057 \mathrm{~m}$. The rocky study area was along intermittent Bear Creek. The dominant vegetation included ponderosa pine, alligator juniper, and willow (Salix sp.). The area was 1.5 ha. Other lizard species present included Urosaurus ornatus, Sceloporus poinsetti, Cnemidophorus sp., Phrynosoma douglassi, and Gerrhonotus kingi.

Both Bear Creek and Cave Creek are usually dry during May and June, usually very dry months in south-eastern Arizona and southwestern New Mexico. Creeks flow in July and August after the start of the rainy season, usually at the beginning of July. Creek beds sometimes are subject to flash floods.

\section{Methods of Observation}

Data were obtained from 1 May to 1 August in 1969,1 May to 15 September in 1970 and 1971, and 1 May to 15 August in 1972. The $S$. virgatus study areas were visited at least twice each week, and the $S$. undulatus areas were visited once or twice each week for 3 to $8 \mathrm{hr}$.

Lizards on study areas were marked permanently by toe-clipping (Tinkle 1967), and by painting their tails with model aeroplane paint. Various combinations of colours and symbols were used for individual recognition. Markrecapture methods were used to determine growth, population structure, and survivorship of lizards on study areas. The proportions of lizards with broken or regenerated tails on study areas were noted as a rough indicator of predation pressure (Pianka 1970; Tinkle \& Ballinger 1972). Information concerning clutch size and number of clutches per season was obtained from lizards sampled in the vicinity of the study areas. A more detailed description of methods used in determining population biology of these lizards will be presented elsewhere, (Vinegar, in preparation).

Seasonal differences in natural intra- and intersexual interactions within all these forms were noted in all 4 years (1969 to 1972). Tests to determine aggression of males and females were performed in 1969 to 1971. In these tests, an intruding lizard was tied by a 75 to $110 \mathrm{~mm}$ string to a stick. The intruder was thus prevented from running away while still leaving some freedom of movement. The tethered lizard was introduced then into the vicinity of a free adult lizard of known sex that usually had been marked previously. The habits and size of the resident, therefore, usually were known. Malemale, male-female, and female-female encounters were staged. The behaviour patterns of both the intruder and resident when the intruder was tethered were compared with those of lizards that naturally encountered each other and with those in which the intruder was introduced simply by releasing the lizard to determine the effects of tethering.

\section{Results}

In general, the timing and behaviour involved in the life histories of these forms of lizard are as follows: mating occurs in the spring; mating usually involves a display by males toward females in which the male bobs his head rapidly up and down ('courtship nods', Carpenter 1962; 'jiggling', Ruibal 1967; 'shuddering', Ferguson 1970). If receptive, the female is quiet and the male mates with her. If not, she avoids him by moving away, by nipping him, or by hopping stiffly on all four legs with her back arched ('sidlehopping', Carpenter 1962). Females lay their eggs by mid-summer, and hatchlings appear in mid-summer to early fall, probably depending on when the eggs are laid, how long 
they are retained in the body of the female, and temperature.

Sceloporus virgatus females lay one clutch per year, with an average clutch size of 9.5 eggs. Sceloporus $u$. consobrinus females lay at least four clutches per year, with an average clutch size of 9.9 eggs. Sceloporus $u$. tristichus lay at least two clutches per year, with an average clutch size of $7 \cdot 2$ eggs.

The sex ratio among $S$. virgatus yearlings (lizards in their first season following the season of hatchling) generally favoured females $(P<0.05$, chi-square test) except in 1971 . The sex ratios among $S$. virgatus two years or older, $S$. $u$. consobrinus, and $S$. $u$. tristichus were not significantly different from $1: 1$.

Relevant aspects of population biology of the forms studied are summarized in Table I. Density and survivorship were determined by census. Not all of the lizards on the $S$. $u$. consobrinus study area could be caught; therefore, the density and survivorship figures for $S$. $u$. consobrinus are approximate. Data for density and survivorship were obtained in 1970, 1971 and 1972 for S. virgatus, and in 1971 and 1972 for S. undulatus. Survivorship data from 1970 to 1971 and 1971 to 1972 are combined here. Survivorship data for the two $S$. virgatus study areas were not significantly different and are combined in Table I. A $1: 1$ sex ratio at the egg stage was assumed. Details of the population biology will be presented elsewhere (Vinegar, in preparation).

The higher incidence of broken or regenerated tails and the lower survivorship found in females of $S$. $u$. consobrinus suggest that they are more vulnerable to predation than females of $S$. virgatus or $S$. $u$. tristichus. The higher fecundity of $S$. $u$. consobrinus may render these females more vulnerable to predation than females of the other forms or males. The different structural environments of the three forms may also effect differential mortality from predation. The many rocks in the $S$. virgatus and $S$. $u$. tristichus study areas provide more continuous cover than the yuccas in the $S . u$. consobrinus area. That is, the space between protective covers is greater in the $S . u$. consobrinus area than in the $S$. virgatus or $S$. $u$. tristichus areas. Potential predators seen in the $S . u$. consobrinus area included loggerhead shrikes (Lanius ludovicianus), road runners

Table I. Summary of Population Biology (Sample Sizes Given in Parentheses)

\begin{tabular}{|c|c|c|c|}
\hline & S. virgatus & S. u. consobrinus & S.u. tristichus \\
\hline Range of densities (per ha) & $61-97$ & $8-10 \cdot 5$ & $26-42$ \\
\hline $\begin{array}{l}\text { Survivorship } \\
\text { Male } \\
\text { egg-1 year } \\
1 \text { year and older }-2 \text { years and older }\end{array}$ & $\begin{array}{l}0.190(331) \\
0.574(129)\end{array}$ & $\begin{array}{l}0.049(246) \\
0.208(29)\end{array}$ & $\begin{array}{l}0.019(208) \\
0.360(25)\end{array}$ \\
\hline $\begin{array}{l}\text { Female } \\
\text { egg-1 year } \\
1 \text { year and older-2 years and older }\end{array}$ & $\begin{array}{l}0.212(331) \\
0.439(123)\end{array}$ & $\begin{array}{l}0.012(246) \\
0.250(20)\end{array}$ & $\begin{array}{l}0.024(208) \\
0.316(38)\end{array}$ \\
\hline $\begin{array}{l}\text { Tail-loss frequency } \\
\text { Male } \\
\text { Female }\end{array}$ & $\begin{array}{l}0.346(156) \\
0.288(163)\end{array}$ & $\begin{array}{l}0.233(43) \\
0 \cdot 514(35)\end{array}$ & $\begin{array}{l}0.325(40) \\
0.167(60)\end{array}$ \\
\hline Fecundity (eggs/clutch $\times$ clutches/year) & $9 \cdot 5 \times 1$ & $9.9 \times 4$ or more & $7 \cdot 2 \times 2$ or more \\
\hline $\begin{array}{l}\text { Coloration } \\
\text { Throat } \\
\text { Male } \\
\text { Female }\end{array}$ & $\begin{array}{l}\text { Blue } \\
\text { Blue-orange }\end{array}$ & $\begin{array}{l}\text { Blue } \\
\text { Blue }\end{array}$ & $\begin{array}{l}\text { Blue } \\
\text { Blue }\end{array}$ \\
\hline $\begin{array}{l}\text { Belly } \\
\text { Male } \\
\text { Female }\end{array}$ & $\begin{array}{l}\text { White } \\
\text { White }\end{array}$ & $\begin{array}{l}\text { Blue } \\
\text { White }\end{array}$ & $\begin{array}{l}\text { Blue } \\
\text { Light blue }\end{array}$ \\
\hline $\begin{array}{l}\text { Mean adult snout-vent length (mm) } \\
\text { Male } \\
\text { Female }\end{array}$ & $\begin{array}{l}50.7(391) \\
59.7(184)\end{array}$ & $\begin{array}{l}60 \cdot 5(38) \\
68 \cdot 4(40)\end{array}$ & $\begin{array}{l}55.9(55) \\
63.3(39)\end{array}$ \\
\hline
\end{tabular}


(Geococcyx californianus), prairie rattlesnakes (Crotalus viridis), patch-nosed snakes (Salvadora hexalepis), gopher snakes (Pituophis melanoleucus), leopard lizards (Crotaphytus wislizenii), and red-tailed hawks (Buteo jamaicensis). Potential predators seen in the $S$. virgatus study areas included Mexican jays (Aphelocoma ultramarina), Sonoran whipsnakes (Masticophis bilineatus), rock rattlesnakes (Crotalus lepidus), black-tail rattlesnakes ( $C$. molossus), black-neck garter snakes (Thamnophis cyrtopsis), and Cooper's hawks (Accipiter cooperii). Potential predators seen in the $S . u$. tristichus study area included Mexican jays and Sonoran whipsnakes.

The results of natural and staged encounters between conspecifics are summarized in Tables II and III. When a male $S$. virgatus encountered another male $S$. virgatus naturally, usually at least one of the males compressed its sides laterally and extended its dewlap (twenty of twenty-eight encounters). A male in this 'challenge' posture (Carpenter 1962) would often perform pushups or move around the other male ('facing off', Carpenter 1962). Sometimes the fights would involve nipping and biting to some degree.

A display of pushups or simply nodding the head without the lizard being in challenge posture was performed often by both sexes of all the forms studied here, either in the presence or absence of other lizards. These simple nods and pushups were considered to be aggressive displays of low intensity.

When a male $S$. virgatus encountered a female naturally, he usually tried to mate with her (forty-four of fifty-seven encounters). The mating sequence usually began with the male approaching the female while nodding his head rapidly and shallowly.

When a male and female $S$. virgatus encountered each other naturally she either exhibited low aggression (i.e. she avoided him, simply bobbed her head, or remained still), sidlehopped or bit. Sidlehopping in $S$. virgatus, however, was usually performed only when the female had oviductal eggs. Only one of the thirteen females that sidlehopped had laid her eggs, but this particular female had laid her eggs within the previous $48 \mathrm{hr}$.

Four natural encounters between females of $S$. virgatus took place after all eggs had been laid. In three encounters females displayed in 'challenge' posture, and in no encounter did females sidlehop. The mode of agonistic display in female $S$. virgatus changed during the breeding season (Vinegar 1972). In staged encounters, females reacted to both male and female intruders in the same manner.

I saw very few natural interactions between individuals of $S$. $u$. consobrinus or of $S$. $u$. tristichus. Of the three encounters between two males of $S$. $u$. consobrinus, one consisted of scuffling within a yucca and the intruder running out quickly. The resident came out a few minutes later. Unfortunately, I could not see the fight. In the second encounter, a male approached a shrub in which there was a larger male, and then ran out quickly. In the third encounter one male bobbed with sides laterally flattened and with dewlap down; the other then ran away. In all four natural encounters between males and females, the male jiggled at the female, and the female responded nonaggressively.

In one natural encounter between two males of S. $u$. tristichus, the males displayed at each other with sides laterally flattened and dewlaps down. In two of four natural encounters between males and females of $S . u$. tristichus, the male jiggled at the female. In one encounter the male, which was immature, bobbed at the female. One natural encounter involved three lizards. First, one adult male and one adult female were seen displaying at each other with sides laterally flattened and dewlaps extended. The male then jiggled, apparently at another male. Another adult female was seen on the same day displaying, apparently at me, by combining sidlehops with pushups in challenge posture. This latter female was killed and found to contain large ovarian eggs.

In addition to the responses in staged encounters listed in Table III, two females of $S$. $u$. tristichus jiggled at introduced males besides displaying with sides laterally flattened and dewlap down. One female also jiggled toward an introduced female. Jiggling was the most common response by males to females, and was usually followed by attempts to mate, both in natural and staged encounters. It may therefore be associated with courtship as Carpenter (1967) indicated. However, the association between jiggling and courtship is not perfect. While jiggling performed by the male $S$. virgatus and the male $S$. $u$. tristichus toward another male in natural encounters (Table III) may be cases of the males mistaking the sex of the other lizard, the performance of jiggling by female $S$. $u$. tristichus cannot be explained thus. 
Table II. Responses of Lizards Toward Conspecifies in Natural Encounters

S. virgatus

BETWEEN MALES
Response:
Challenge display
Jiggling
Resident chases
Intruder runs away
Head bobbing
Total no. males

BETWEEN MALES AND FEMALES

Male response:

Challenge display

Jiggling

Head bobbing or no apparent interaction

Total no. males

Female response:

Challenge display

Sidlehopping

Nipping without challenge

Other (low or no aggression)

Total no. females

BETWEEN FEMALES

Response:

Challenge display

Sidlehopping

Chasing

Other

Total no. females
S. u. consobrinis

S. u. tristichus
1
1
1
0
4

1
2
1
4

$\begin{array}{ll}1 & 1 \\ 0 & 1 \\ 0 & 1 \\ 2 & 0 \\ 0 & 0 \\ 6 & 4\end{array}$

0

4

3

0

0

0

3

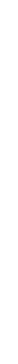

Table III. Responses of Residents to Conspecifics in Staged Encounters

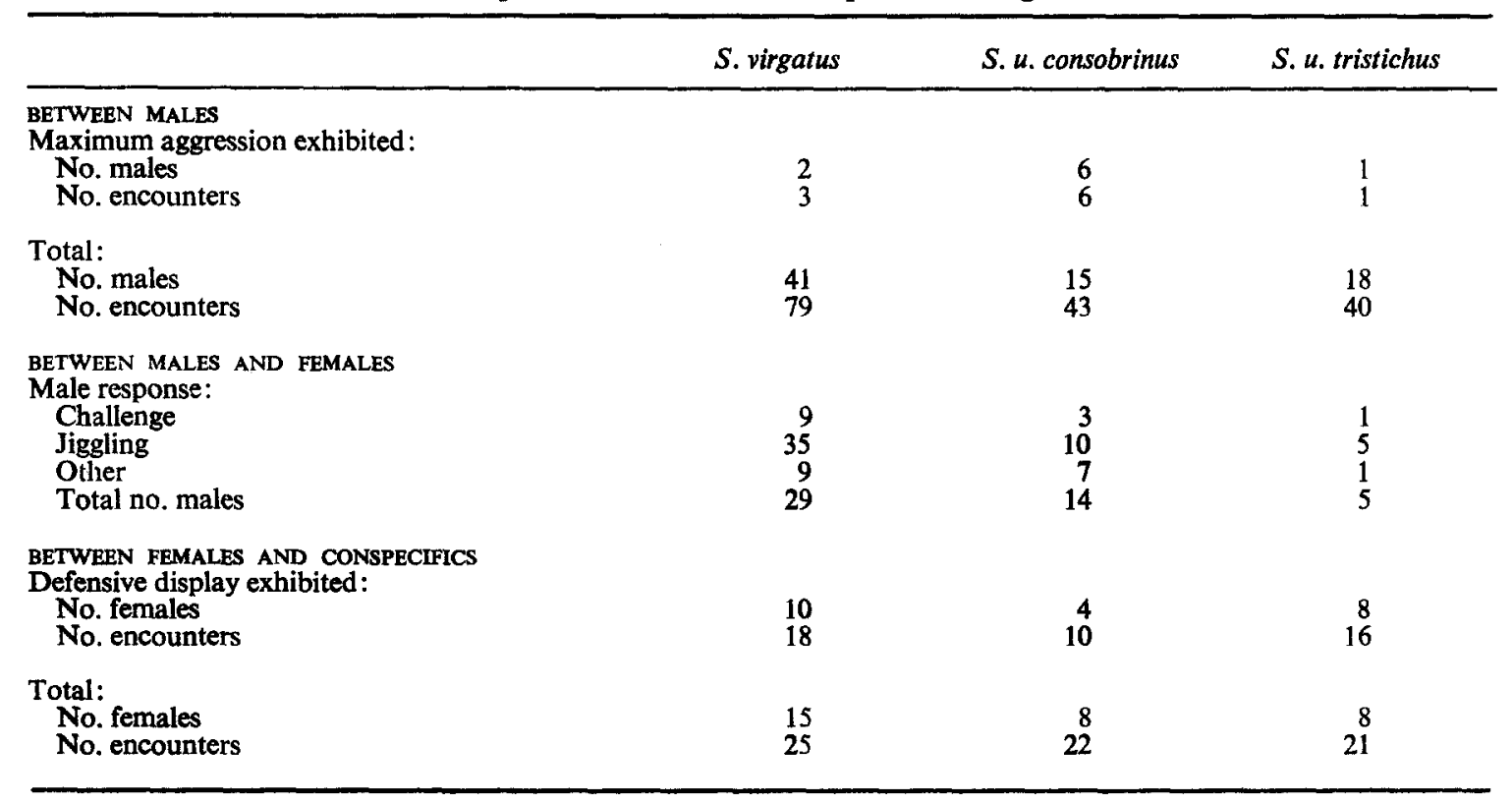


'Jiggling', therefore, may occur in contexts other than courtship (Vinegar 1972).

In staged encounters, the responses of resident males of $S$. virgatus and $S$. $u$. tristichus did not differ whether the intruder was tethered or simply was released near the resident insofar as evoking maximum aggression was concerned. The results from both types of introductions therefore are combined in Table III for these forms. Simply releasing the intruder did not work with $S$. $u$. consobrinus, however, because the intruder would immediately run into a yucca and could not be recaptured. Maximum (potential) aggression could not be obtained by this method of introducing intruders; therefore, results of staged encounters with $S$. $u$. consobrinus in Table III are only those in which the intruder was tethered.

In the responses of males toward artificially introduced males, each resident was counted only once in obtaining its score. The score consisted of the maximum aggression obtained from that male. Biting the opponent and maintaining the bite-hold was considered the most aggressive action in a fight when the bitehold was accompanied by challenge display. Occasionally males court an introduced male, evidently mistaking the intruder for a female, then bite the intruder in attempts to mate. Therefore, bite-holding was considered as highly aggressive only if the male biting also performed 'challenge' displays which indicated that the resident was responding to the intruder as to a male. The number of males of each form that held their male opponents by biting is given in Table III. Sceloporus u. consobrinus are more potentially aggressive by this criterion than either $S$. $u$. tristichus $(P=0.023$, Fisher exact probability test) or $S$. virgatus $(P<0.01$, chisquare test for two independent samples, Siegel 1956).

In the staged encounters with resident females, the responses of $S . u$. tristichus females were the same whether or not the intruder was tethered. The results of both types of encounter therefore are combined in the results of $S$. u. tristichus. In staged encounters with $S$. $u$. consobrinus female residents, all intruders were tethered for the reasons stated above. In staged encounters with $S$. virgatus female residents, the resident seemed slightly more likely to hide if the intruder were tethered. Therefore, only the results of $S$. virgatus encounters in which the intruder was not tethered are included in Table III.
A female was considered aggressive if she either sidlehopped or displayed in 'challenge' posture toward any introduced conspecific during the breeding season. This restriction to breeding season, i.e. when the females are likely to have oviductal eggs, in analysing results was made because of evidence that the behaviour of $S$. virgatus females toward conspecifics is different from behaviour outside the breeding season. The restriction to breeding season helped to standardize my results. The criterion of aggression, sidlehopping, or challenge display, is a measure of the female's tendency to 'stand her ground' or to defend actively as opposed to running away or permitting another lizard to come close to her. The number of females which sidlehopped or displayed in challenge posture of those tested and the number of encounters performed are given in Table III. The difference in aggression between $S$. $u$. tristichus and $S$. $u$. consobrinus, based on number of females tested displaying aggressively, is significant $(P=0.038$, Fisher exact probability test, Siegel 1956).

\section{Discussion}

The relative degree of intraspecific aggression in the three forms within sexes seems to be related to how brightly coloured the sex is in comparison with the opposite sex. The greatest degree of sexual dicromatism in the three forms appears to be in $S$. $u$. consobrinus where the males have blue belly patches and the females have white bellies; these males also have the highest potential aggression of males of the three forms. The most brightly coloured of the females appear to be those of $S$. $u$. tristichus, which have blue belly patches and were the most aggressive. Females of $S$. $u$. consobrinus were the least aggressive of the females. I wish to be very cautious, however, in drawing any conclusions concerning the relationship of aggression with degree of bright coloration. Gravid females of $S$. virgatus with orange throat patches could be considered brightly coloured compared to the males. My judgment of colour and degree of brightness is very subjective and may have no relation to how the lizard sees or interprets colour. For example, the apparent difference in coloration between sexes certainly is not the only factor involved in sex recognition. Males of $S$. virgatus and $S$. $u$. consobrinus usually respond to conspecific females appropriately even if orange throat patches of $S$. virgatus were painted blue (Vinegar 1972) or if the white 
bellies of $S$. $u$. consobrinus were painted blue (Vinegar, unpublished data). Therefore, colour is not the only factor involved in sex recognition in these lizards and is probably not the only factor involved in aggression. The degree of both aggression and bright coloration would be results of other selection pressures (discussed below).

Differences in aggression of males of the three forms may be related to density (Table I). The higher densities of $S$. virgatus and $S$. $u$. tristichus may render violent or escalated fighting less adaptive than at lower densities. If a male spends a lot of time and energy in fighting each male it meets, then in higher densities it would meet more lizards and spend more energy in fighting (assuming home range size does not decrease), which would leave less time and energy available for food-getting, mating, and other adaptive activities. Moreover, if he fights violently each time he meets another male, he runs more risk of getting hurt when the density is high than when the density is low. Milstead (1970) suggested that display was advantageous in conserving energy. Maynard Smith \& Ridpath (1972) discussed the conditions under which ritualized and escalated fighting would be adaptive. They quoted an unpublished analysis by G. R. Price in which escalated fighting would be evoked as a response to being hurt. I would broaden the conditions; escalated fighting would be evoked when more would be gained by continuing to fight than by conserving energy, In $S$. u. consobrinus, not defeating an opponent would mean having to share the yucca and its resources with a competitor or having to leave the yucca. The resource in shortest supply for a male $S$. $u$. consobrinus would be female $S$. $u$. consobrinus. Low density implies there is a relatively longer distance between females than in the other forms. Moreover, a male forced to leave his yucca would have to travel across open space to reach another yucca or some suitable cover and run the risk of predation. When $S$. $u$. consobrinus lizards are travelling between yuccas, they are slow to leave the vicinity of the yucca, then run very quickly to the next yucca. They are extremely difficult to catch when they are running between yuccas. Such behaviour would be adaptive particularly when predation pressure is high. A male would have more to gain by fighting a persistent intruder than by leaving his yuccas or by sharing it with a competitor. The only time I saw two non-combative males in the same yucca was when one of the males was adult and the other was a small, immature male with very pale belly patches. This exception indicates that the young male probably was not a competitor in the eyes of the adult. The tendency for intruding males of $S$. $u$. consobrinus to run away from a resident in both natural and staged encounters suggests that selection favours retreat in intruders because of the high potential aggression of the residents. In one case, the bite-holding of the resident on the head of a tethered intruder resulted in the death of the intruder. The wound had bled, and the subsequent infection probably killed the intruder.

The high degree of aggression in females of $S$. $u$. tristichus than in $S$. $u$. consobrinus may be related to density and predation. The low density (possibly the result of predation), the relatively large size of female $S . u$. consobrinus, and the higher fecundity of $S$. $u$. consobrinus (see Vinegar for details 1973) suggests that this population is well below the carrying capacity $(K)$ of the environment and that food is plentiful. Therefore, there should be little competition between these females for food. Females of $S$. $u$. consobrinus probably seldom are challenged by males or other females during the breeding season. Therefore, there should be little selection pressure for them to be defensive during the breeding season. High predation would select against females which move around unnecessarily and thus encounter predators as well as other lizards. Sceloporus $u$. tristichus females, however, are higher in density. Fewer resources such as food and egg-laying sites may be available. Therefore, there may be greater selection for defensive behaviour. Less predation may mean reduced selection pressure against mobility and bright colours in females. Higher mobility means they would be more likely to encounter each other than would females of $S . u$. consobrinus.

Higher aggression in lizards of lower density has been reported for Uta stansburiana (Tinkle 1967) and Sceloporus merriami (Milstead 1970). Milstead, however, gives a different explanation from mine for $S$. undulatus. He suggests that the food supply was lower where there was lower density and that higher aggression spaced the lizards in relation to the available food supply. His explanation does not fit the $S$. undulatus situation where higher aggression was found in females with higher density, but higher potential aggression was found in males with lower density. Higher aggression with lower density 
has been reported in other animals; e.g. crickets (Alexander 1968), dragonflies (Panujen 1966), locusts (Kennedy 1961), and salmon (Fenderson \& Carpenter 1971).

Although some correlations between density, coloration, and level of aggression were found in the lizards studied, it is too early to draw conclusions concerning the evolution of aggressive behaviour in relation to environmental biology of lizards. Both the behaviour and ecological aspects of more species of lizards must be studied before conclusive generalities may be made.

\section{Acknowledgments}

This study constitutes part of a thesis submitted for the Ph.D. degree at The University of Michigan. Dr Richard D. Alexander, Dr Nelson G. Hairston and, in particular, Dr Donald W. Tinkle gave very helpful comments at various stages in the research and writing of the manuscript. The research was supported (in part) by grants from the National Science Foundation, GB-8212, GB-13104, and GB-25986, to N. G. Hairston, The University of Michigan, for research in Systematic and Evolutionary Biology; in part by a grant from the National Science Foundation, GB-29131, to D. W. Tinkle, and in part by a grant from the Rackham Graduate Student Dissertation Research Fund. I am grateful to the American Museum of Natural History for use of the facilities of the Southwestern Research Station; Mr Vincent Roth and the other members of the staff of SWRS were very helpful during the study. I thank Jim Culberson of Lordsburg for permitting me to study lizards on his land. Various people, including Allen Vinegar, Lewis Herlin, David Smith, and Guido Dingerkus, helped occasionally with field work.

\section{REF ERE N C ES}

Alexander, R. D. (1968). Life cycle origins, speciation, and related phenomena in crickets. $Q$. Rev. Biol., 43, 1-41.
Carpenter, C. C. (1962). Patterns of behavior in two Okjahoma lizards. Am. Midl. Nat., 67, 132-151.

Carpenter, C. C. (1967). Aggression and social structure in iguanid lizards. In: Lizard Ecology, A Symposium (Ed. by W. W. Milstead), pp. 87-105. Columbia: University of Missouri Press.

Fenderson, O. C. \& Carpenter, M. R. (1971). Effects of crowding on the behaviour of juvenile hatchery and wild landlocked salmon (Salmo salar L.). Anim. Behav., 19, 439-447.

Ferguson, G. W. (1970). Mating behaviour of the sideblotched lizards of the genus Uta (Sauria: Iguanidae). Anim. Behav., 18, 65-72.

Kennedy, J. S. (1961). Continuous polymorphism in locusts. In: Insect Polymorphism. Symposia of the Royal Entomological Society of London, 1. $80-90$.

Maynard Smith, J. \& Ridpath, M. G. (1972). Wife sharing in the Tasmanian native hen, Tribonyx mortierii: a case of kin selection? Am. Nat., 106, 447-552.

Milstead, W. W. (1970). Late summer behavior of the lizards Sceloporus merriami and Urosaurus ornatus in the field. Herpetologica, 26, 343-354.

Panujen, V. I. (1966). The influence of population density on the territorial behavior of Leucorrhinia rubicunda L. (Odon. Libelludiae). Ann. Zool. Fenn., 3, 40-52.

Pianka, E. R. (1970). Comparative autecology of the lizard Cnemidophorus tigris in different parts of its geographic range. Ecology, 51, 703-720.

Ruibal, R. (1967). Evolution and behavior in West Indian anoles. In: Lizard Ecology, A Symposium (Ed. by W. W. Milstead), pp. 116-140. Columbia: University of Missouri Press.

Siegel, S. (1956). Nonparametric Statistics for the Behavioral Sciences. New York: McGraw-Hill.

Tinkle, D. W. (1967). The life and demography of the side-blotched lizard, Uta stansburiana. Misc. Publs Mus. Zool. Univ. Mich., 132, 1-182.

Tinkle, D. W. \& Ballinger, R. E. (1972). Sceloporus undulatus: a study of the intraspecific comparative demography of a lizard. Ecology, 53, 570-584.

Vinegar, M. B. (1972). The function of breeding coloration in the lizard, Sceloporus virgatus. Copeia, $1972,660-664$.

Vinegar, M. B. (1973). Evolution of Life Fistory Phenomena in Three Forms of the Lizard Genus Sceloporus. Ph.D. thesis, University of Michigan.

(Received 3 October 1973; revised 5 March 1974; MS. number: A1488) 